\title{
Insulin resistance and insulin deficiency in the pathogenesis of Type 2 (non-insulin-dependent) diabetes mellitus: errors of metabolism or of methods?
}

\author{
L.C.Groop ${ }^{1}$, E. Widén ${ }^{2}$, E. Ferrannini ${ }^{3}$ \\ ${ }^{1}$ Department of Endocrinology, Malmö General Hospital, University of Lund, Malmö, Sweden \\ ${ }^{2}$ Fourth Department of Medicine, Helsinki University Hospital, Helsinki, Finland \\ ${ }^{3}$ Metabolism Unit, CNR Institute of Clinical Physiology, University of Pisa, Pisa, Italy
}

There is strong evidence that Type 2 (non-insulin-dependent) diabetes mellitus is genetic in origin. Thus, the concordance rate for the disease in identical twins approaches $90 \%$ (when both twins have been examined), and the lifetime risk of developing diabetes is about $40 \%$ in the offspring of one diabetic parent $[1,2]$.

The key question is, what is inherited in Type 2 diabetes? Patients with manifest diabetes usually have evidence of both insulin resistance (in muscle and liver) and impaired beta-cell function. An additional confounder is that hyperglycaemia itself can further impair insulin sensitivity as well as insulin secretion [3]. Therefore, studies in overtly diabetic patients do not establish which defect is inherited and what abnormalities develop as a consequence of chronic hyperglycaemia.

To circumvent this problem, investigators have examined persons at high risk of developing Type 2 diabetes, i. e. offspring or siblings of patients with the disease [4-18]. The results have been discordant, with some advocating insulin deficiency $[4-6,15,18]$ and others insulin resistance $[7-14,16,17]$ as the inherited abnormality. Heterogeneity of the disease and differences in patient populations have been popular arguments with which to explain the discrepancy. While it is clear that Type 2 diabetes is heterogeneous [19], and that ethnic differences do exist, it is uncertain whether the basic argument can be reconciled on these grounds alone. Here, we discuss the possibility that the various methods that have been used to assess insulin sensitivity and beta-cell function may have a role in explaining the divergent results.

\section{Measuring insulin sensitivity}

Insulin sensitivity has been estimated by several different methods, which are recalled in Table 1 . They include highdose glucose infusion (GIT) [4, 5], low-dose glucose infusion (CIGMA) [6, 20], the intravenous glucose tolerance test (IVGTT) $[10,14,21]$ and its subsequent analysis with the minimal model approach (FSGIT) [13, 17, 22], the euglycaemic [7, 9, 16, 23] and hyperglycaemic clamp [18, 23], a fixed infusion of glucose and insulin [8], and a combined infusion of somatostatin, insulin and glucose (or insulin suppression test (IST)) [12].

Several of these techniques (IVGTT, FSIGT, GIT, CIGMA, hyperglycaemic clamp) also provide estimates of insulin secretion. The euglycaemic insulin clamp has been considered to be the "gold standard" for measuring insulin sensitivity, the major advantage being that measurements are performed at a steady state of both insulin and glucose concentrations. Another major advantage of the euglycaemic clamp is that it can be easily combined with the infusion of labelled glucose (to allow measurements of hepatic glucose production and its sensitivity to insulin) and indirect calorimetry (to estimate intracellular glucose disposition, i. e. oxidation vs storage).

Methods that measure insulin sensitivity should satisfy at least five requirements. First, the insulin levels achieved should be high enough to stimulate glucose metabolism and detect possibly small differences in sensitivity of glucose uptake to insulin. When using an exogenous insulin infusion rate of $1 \mathrm{mU} \cdot \mathrm{min}^{-1} \cdot \mathrm{kg}^{-1}$ (or $40 \mathrm{mU} \cdot \mathrm{min}^{-1} \cdot \mathrm{m}^{-2}$ $\left[280 \mathrm{pmol} \cdot \mathrm{min}^{-1} \cdot \mathrm{kg}^{-1}\right]$, resulting in steady-state levels of $400-500 \mathrm{pmol} \cdot \mathrm{I}^{-1}$ ), the sensitivity and reproducibility of the euglycaemic clamp are sufficient to pick up systematic differences upwards of approximately $10 \%$. For comparison, the CIGMA technique achieves insulin concentrations between $10-20 \mu \mathrm{U} \cdot \mathrm{ml}^{-1}\left(70-140 \mathrm{pmol} \cdot \mathrm{l}^{-1}\right)$, which represent a weak stimulus for peripheral glucose uptake.

Second, it is desirable for the test to distinguish between peripheral and hepatic insulin sensitivity. Since these pathways may be affected differentially in the early stages of insulin resistance, their separate quantitation may be important. A glance at the dose-response curves for stimulation of glucose uptake and suppression of hepatic glucose production (HGP) by insulin in non-diabetic and Type 2 diabetic subjects, shows that significant differences in glucose uptake between groups are not seen until the insulin concentrations have risen to levels of about $30-40 \mu \mathrm{U} \cdot \mathrm{ml}^{-1}\left(210-280 \mathrm{pmol} \cdot \mathrm{1}^{-1}\right)$. In contrast, suppression of HGP is seen at much lower insulin concentrations (Fig.1) [24]. If suppression of HGP during the test 
Table 1. Methods used to assess insulin sensitivity and insulin secretion

\begin{tabular}{|c|c|c|c|c|c|c|}
\hline Method & Ref. & $\begin{array}{l}\text { Glucose } \\
\text { infusion } \\
\text { bolus } \\
\left(\mu \mathrm{mol} \cdot \mathrm{kg}^{-1} \cdot \mathrm{min}^{-1}\right)\end{array}$ & $\begin{array}{l}\text { Insulin } \\
\text { concentration } \\
\left(\mathrm{mU} \cdot \mathrm{kg}^{-1} \cdot \mathrm{min}^{-1}\right)\end{array}$ & $\begin{array}{l}\text { Glucose } \\
\left(\mathrm{mmol} \cdot \mathrm{1}^{-1}\right)\end{array}$ & $\begin{array}{l}\text { Insulin } \\
\left(\mu \mathrm{U} \cdot \mathrm{ml}^{-1}\right)\end{array}$ & $\begin{array}{l}\text { Time }^{\mathrm{a}} \\
\text { (min) }\end{array}$ \\
\hline CIGMA & 20 & 28 & - & $7-11$ & $7-15$ & 60 \\
\hline $\begin{array}{l}\text { IVGTT } \\
\text { (Minimal model) }\end{array}$ & $\begin{array}{l}13,21 \\
22\end{array}$ & $2.8 \mu \mathrm{mol} \cdot \mathrm{kg}^{-1 \mathrm{~b}}$ & - & $v^{c}$ & $15-50$ & B \\
\hline $\begin{array}{l}\text { Hyperglycaemic } \\
\text { clamp }\end{array}$ & 23,30 & adjusted & - & $10-12$ & $30-100$ & $120-180$ \\
\hline IST & $12^{\mathrm{d}}$ & 33 & 1 & $6-8$ & $70-110$ & 240 \\
\hline Glucose/Insulin & 11 & 33 & 0.83 & $4-6$ & $40-70$ & 45 \\
\hline
\end{tabular}

GIT, Glucose infusion test; CIGMA, continuous infusion of glucose with model assessment; IVGTT, intravenous glucose tolerance test; IST, insulin suppression test; B, bolus; $v$, variable

a Time of infusion; ${ }^{b}$ given as an intravenous bolus injection; ${ }^{c}$ in pa- tients with impaired insulin secretion, a bolus of insulin or tolbutamide is necessary; ${ }^{\mathrm{C}}$ endogenous insulin secretion suppressed by somatostatin

the minimal model assumes that glucose kinetics are monocompartmental [22], and that insulin action takes place in a 'remote' compartment. The former assumption is clearly untenable [25]; the latter can possibly be defended for insulin effects on peripheral tissues, but does not accurately describe the effect of insulin on the liver.

Fifth, many of the tests result in a rise in plasma glucose levels, measurements of glucose uptake then being made during hyperglycaemia. Glucose clearance is influenced by the prevailing plasma glucose level, especially at low insulin concentrations [26]. Therefore, hyperglycaemia may present a greater problem with methods resulting in only modest increments in plasma insulin. Furthermore, the plasma glucose concentration is liable to rise more in glucose-intolerant than in glucose-tolerant individuals. Two sets of results illustrate this important point. (A) Activation of glycogen synthase by insulin is impaired in the offspring of patients with Type 2 diabetes [16,27]. This defect can, however, be overcome by raising the plasma glucose concentration [28]. The explanation is the allosteric activation of an enzyme that is resistant to covalent activation by insulin. (B) During euglycaemic hyperinsulinaemia, first-degree relatives of Type 2 diabetic patients with normal glucose tolerance showed a $33 \%$ reduction in insulinstimulated glucose metabolism as compared with nondiabetic control subjects. During a hyperglycaemic clamp, on the other hand, the difference between probands and control subjects was only $14 \%$, and no longer reached statistical significance [29]. The interpretation of the latter result is equivocal. Are the relatives as insulin sensitive as the control subjects, or is hyperglycaemia more effective in the relatives than in the control subjects? To further complicate the issue, endogenous plasma insulin concentrations are not clamped during a hyperglycaemic clamp, and in fact they were found to be higher in the insulin-resistant relatives than in the control subjects. Theoretically, dividing the glucose uptake rate by the plasma insulin concentration would correct for this difference [30]. This operation, however, assumes that endogenous insulin lev- 
els are stable, and that they are linearly related to glucose metabolism. Neither of these premises holds entirely true. In response to square-wave hyperglycaemia, the pattern of endogenous insulin release is rarely in steady state. Furthermore, the insulin dose-response for whole-body glucose uptake is sigmoidal, with a segment where it is linearly related to the log of peripheral plasma insulin concentrations (Fig.1). Thus, insulin sensitivity studies performed during hyperglycaemic conditions are more likely to miss small differences than euglycaemic methods. Incidentally, the highest blood glucose levels are achieved with the GIT technique $\left(15-20 \mathrm{mmol} \cdot 1^{-1}\right)$. These concentrations are likely to influence glucose uptake more in the "low" than in the "high" insulin responders $[4,5]$.

That the euglycaemic clamp represents the "gold standard" with which to measure insulin sensitivity could be questioned on the grounds that the test creates unphysiological conditions (e.g., stable hyperinsulinaemia), which do not represent everyday life. This is certainly true, and this reservation applies to all the other methods in Table 1. More important is to understand the extent to which the test deviates from normal physiology. During the most common version of the euglycaemic clamp (insulin infused at a rate of $7 \mathrm{pmol} \cdot \mathrm{min}^{-1} \cdot \mathrm{kg}^{-1}$ for $2-3 \mathrm{~h}$ ), independent estimates of regional glucose disposal indicate that over $90 \%$ of total metabolised glucose $(\sim 35 \mu \mathrm{mol}$. $\min ^{-1} \cdot \mathrm{kg}^{-1}$ in a healthy adult) ends up in peripheral tissues, among which skeletal muscle mass accounts for 50 $60 \%$ of total peripheral uptake. About $40 \%$ of total glucose metabolism is complete oxidation, the remainder is non-oxidative glucose disposal, of which glycogen storage represents about $90 \%$ [31]. Glucose ingestion, on the other hand, elicits a lower degree of systemic insulinisation, which in turn results in a smaller stimulation of peripheral glucose clearance. The concurrent glucose-induced hyperglycaemia, on the other hand, provides a greater substrate pressure for glucose uptake than euglycaemia. The net result is variable, depending on the respective time courses of hyperglycaemia and insulinstimulated peripheral glucose disposal. For example, Table 2 reports data compiled from two human studies in which double-tracer measurements of endogenous and oral glucose kinetics were combined with direct estimation of muscle [32] or splanchnic [33] glucose uptake by catheter. Both studies estimated that peripheral ( $=$ extrasplanchnic) tissues account for approximately $85 \%$ of whole-body glucose disposal in the fasting state, and that this declines to approximately $70 \%$ during the absorptive period. Conversely, the percent contribution of splanchnic tissues increases from $15 \%$ in the fasting state to approximately $30 \%$ during the absorptive period. This shift in regional glucose utilisation follows from the fact that ingested glucose is preferentially channelled to the splanchnic organs via the portal circulation. Although splanchnic glucose uptake is not insulin stimulatable, portal hyperglycaemia, coupled with an increase in splanchnic blood flow, drives four times more glucose into the splanchnic organs than in the basal state, while portal hyperinsulinaemia halves HGP (Table 2). The quantitative role of peripheral tissues, however, remains predominant, as skeletal muscle responds to peripheral hyperinsulinaemia with
Table 2. Handling of an oral glucose load in normal humans

\begin{tabular}{llc}
\hline Basal state & $5 \mathrm{~h}^{\mathrm{a}}$ & $3.5 \mathrm{~h}^{\mathrm{b}}$ \\
\hline Hepatic glucose production & $48 \pm 2$ & $33 \pm 1$ \\
Total glucose uptake (a) & $48 \pm 2$ & $33 \pm 1$ \\
Splanchnic glucose uptake (b) & $(7)$ & $5 \pm 1$ \\
Peripheral glucose uptake (a-b) & $(41)$ & $28 \pm 1$ \\
- Brain glucose uptake (c) & $(25)$ & $(17.5)$ \\
- Muscle glucose uptake (d) & $9 \pm 2$ & $(6.3)$ \\
- Residual glucose uptake (a-b-c-d) & $(7)$ & $(4.2)$ \\
Splanchnic (\% of total) & $15 \%$ & $14 \%$ \\
Peripheral (\% of total) & $85 \%$ & $86 \%$ \\
Muscle (\% of total) & $19 \%$ & $19 \%$ \\
Ingested glucose load (1 g. $\left.\mathrm{kg}^{-1}\right)$ & $79 \pm 3$ & $68 \pm 3$ \\
Absorptive state & & \\
\hline Hepatic glucose production & $26 \pm 1$ & $15 \pm 2$ \\
Oral glucose appearance & $49 \pm 1$ & $50 \pm 4$ \\
Total glucose uptake & $75 \pm 1$ & $67 \pm 4$ \\
Splanchnic glucose uptake & $(22 \pm 1)$ & $19 \pm 4$ \\
Peripheral glucose uptake & $(53 \pm 1)$ & $48 \pm 6$ \\
- Brain glucose uptake & $(25)$ & $(17.5)$ \\
- Muscle glucose uptake & $41 \pm 3$ & $(28.7)$ \\
- Residual glucose uptake & $(-13)$ & $(1.8)$ \\
Splanchnic (\% of total) & $29 \%$ & $28 \%$ \\
Peripheral (\% of total) & $71 \%$ & $72 \%$ \\
Muscle (\% of total) & $55 \%$ & $43 \%$ \\
\hline All values are given in gram & & \\
\hline
\end{tabular}

All values are given in grams. Values in parentheses are estimates, not direct measurements.

a 5 -h, double-tracer study combined with forearm catheterization by Mitrakou et al., [30]

b $3.5 \mathrm{~h}$, double-tracer study combined with splanchnic catheterization by Ferrannini et al. [31]

a 4-5-fold increase in glucose uptake. Thus, in comparison with the euglycaemic clamp, oral glucose administration favours glucose disposal by splanchnic tissues, and is relatively less effective in inhibiting HGP. With both tests, however, control of glucose homeostasis relies heavily on the ability of insulin-sensitive peripheral tissues to clear glucose from the plasma.

\section{Measuring insulin secretion}

The assessment of insulin secretory dynamics is less established. There are several reasons for this. Firstly, glucose is the principal but not the only insulin secretagogue, aminoacids and, to a lesser extent, non-esterified fatty acids (NEFA) are also capable of stimulating insulin release. Furthermore, a host of gastrointestinal hormones (e.g., gastric inhibitory polypeptide) potentiate the insulin response to glucose. Secondly, information on pancreatic insulin secretion is usually inferred from the time course of peripheral plasma insulin concentrations. To reconstruct the corresponding rates of pancreatic insulin secretion, it is necessary to measure both insulin and C-peptide kinetics to be used in the context of deconvolution or system model methods of analysis [34]. Thirdly, insulin secretion responds to changes in plasma glucose concentrations as well as to the rate of such changes [35]. Finally, even under steady-state conditions of hyperglycaemia, the beta-cell response is intrinsically biphasic (if not multiphasic). 


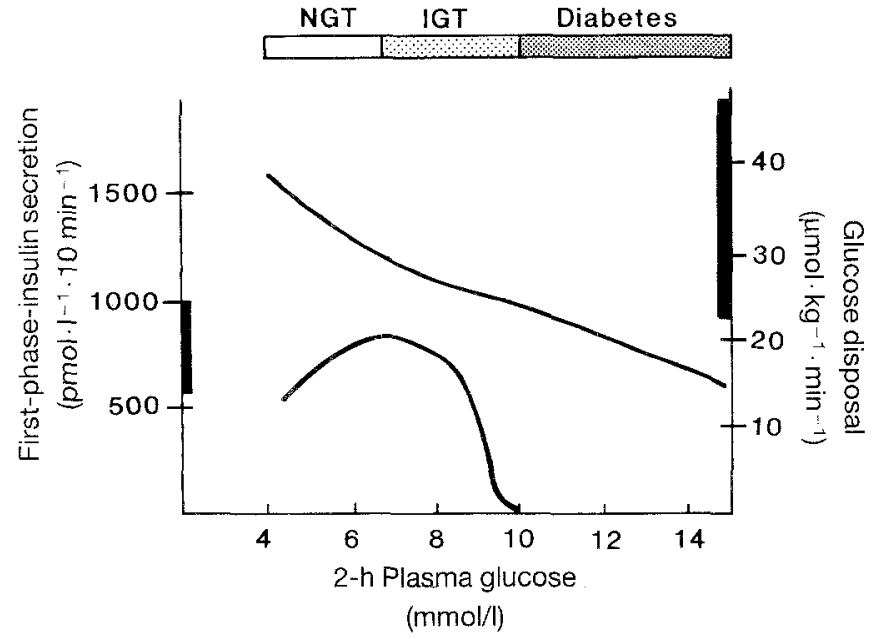

Fig. 2. First-phase insulin response and glucose disposal rate (at an insulin infusion rate of $315 \mathrm{pmol} \cdot \mathrm{min}^{-1} \cdot \mathrm{kg}^{-1}$ ) are plotted against the 2 -h blood glucose concentration during an oral glucose tolerance test. Both first-phase insulin response $(r=-0.53, p=0.008, n=56)$ and glucose disposal rate $(r=-0.37, p=0.002, n=69)$ are inversely related to 2 -h blood glucose levels. Shaded rectangles on the $y$ axes represent mean \pm 1 SD of first-phase insulin response (left) and glucose disposal rate (right) in healthy control subjects. NGT, normal glucose tolerance; IGT, impaired glucose tolerance

A first and second phase of insulin response can usually be identified following a continuous infusion of glucose. With the IVGTT, only the first (early) phase of insulin response can be reliably (and reproducibly) determined, while the second phase is dependent upon the glucose concentrations achieved, and thereby, on glucose clearance. The same problem applies to the OGTT, in which the measurements are performed under non-steady-state conditions of glucose absorption, entero-insular activity, and glucose utilisation. The hyperglycaemic clamp suffers from the problem that the insulin concentrations elicited by the conventional $+7 \mathrm{mmol} \cdot \mathrm{I}^{-1}$ hyperglycaemic clamp are far below those considered as maximal [36]. If one postulates reduced beta-cell mass (capacity) as the earliest defect leading to Type 2 diabetes, the test may not be able to detect it. Another approach has been to perform doseresponse studies with increasing plasma glucose concentrations [36, 37], but even then it has been difficult to determine the maximal insulin response [37]. To circumvent this problem, another insulin secretogogue such as arginine [36] or glucagon [9] can be added to the glucose stimulus.

It is important to mention that, in addition to the amount of insulin secreted by the beta-cell the temporal pattern of the secretory response (cycles entrained to analogous glucose oscillations) is key to glucose homeostasis [38] and may be specifically altered in diabetes [39].

Finally, it can be argued that what is measured by commercially available radioimmunoassays is not insulin, but rather a mixture of insulin, proinsulin and its split products [40]. We could not, however, observe any disproportionate increase in proinsulin in insulin-resistant relatives during a hyperglycaemic clamp [41].

\section{Selection of subjects}

Ethnic differences are likely to play a major role in determining insulin sensitivity. Osei and co-workers [42] have reported lower rates of glucose metabolism in American Blacks than in Caucasians. Asian Indians seem to be more insulin resistant than Caucasians [43]. Ethnic admixture of study populations may therefore obscure the results. Associated conditions may also influence the degree of insulin sensitivity. Thus, hypertension per se is associated with insulin resistance [44], and skewness with respect to presence of hypertension in probands and controls can certainly influence the results of these comparisons.

Obesity may be another confounding factor, and several authors have reported normal insulin sensitivity in non-obese Type 2 diabetic subjects $[45,46]$. The family history of Type 2 diabetes can also influence the results. In this respect, however, having one parent who developed Type 2 diabetes at the age of 75 years may not have the same meaning as having two parents who acquired the disease at the age of 50. Incidentally, it is interesting to note that both the low- and high-insulin responders in the studies by Cerasi and Luft [5] were rather lean (relative body weight below $100 \%$ ). However, more high- than low-insulin responders had a first degree family history of Type 2 diabetes $(36 \%$ vs $6 \%, p<0.05)$. The low-insulin responders in these studies, therefore, differ markedly from the rather obese offspring of patients with Type 2 diabetes included in other studies.

\section{Conclusions}

In summary, we submit that the available techniques for measuring insulin sensitivity, despite their differences in rationale and performance, can provide a satisfactory answer to a definite question: what is the response to the hormone (in individual tissues or at the whole body level) under controlled conditions of stimulus (insulin) and substrate (glucose)? In contrast, the techniques for measuring insulin secretion are generally less well developed and validated, possibly because the question has been less definite. What is the hypothesis when we measure insulin secretion in Type 2 diabetes (or, rather, in prediabetic states)? Is the capacity (maximal response) of pancreatic islets reduced? Is the sensitivity to glucose impaired? Are the kinetics of insulin release (early vs late phase, responsivity to rate changes, cyclicity of insulin output) different? If there is a functional defect, is this the expression of all the beta-cells carrying the same defect or the selective loss of special beta-cell subpopulations? Consider the following two paradoxes. First, deletion of first-phase insulin response to intravenous glucose has long been regarded as an early sign of beta-cell dysfunction, having some predictive value for subsequent development of diabetes. Under normal life circumstances, however, there is no such thing as an early-phase insulin response (first 10 min following an intravenous glucose bolus): how does such a phase relate to normal beta-cell function and its changes over time? Second, there is good evidence that chronic hyperglycaemia intoxicates beta-cells, thereby introducing a pa- 
thogenetic loop between insulin action and insulin secretion. How much hyperglycaemia is toxic for how long is a functional aspect of human beta-cells which is not understood, yet it is clear that diabetes does not follow insulin resistance of long duration unless the beta-cell fails. Thus, what is inherited and what is acquired of the putative defect(s) in insulin secretion?

Figure 2 is a graphic representation of the dilemma. When a large number of observations are compiled, it is evident that both insulin sensitivity and first-phase insulin response are an inverse function of 2 -h (post-OGTT) plasma glucose concentrations (i. e. glucose tolerance). However, insulin sensitivity declines slowly and monotonically with increasing 2 -h plasma glucose levels. In contrast, first-phase insulin response initially rises, then plateaus until plasma glucose approaches $8.5 \mathrm{mmol} \cdot \mathrm{l}^{-1}$, whereafter it falls abruptly to a flat nadir (inverted U shape). What is responsible for this discontinuous behaviour? What is so critical about blood glucose levels between 8.5 and $9.5 \mathrm{mmol} \cdot 1^{-1}$ to knock out acute insulin response? Is this step-down in acute insulin response an imperfect marker of an otherwise continuous decline in overall beta-cell function? Clearly, until more refined techniques to model in vivo insulin secretion are developed and applied, this observation is likely to remain unexplained. A corollary of this finding is that, when studying IGT states inclusion of subjects with 2-h blood glucose levels less than $8.5 \mathrm{mmol} \cdot \mathrm{l}^{-1}$ will favour a defect in insulin sensitivity as the pathogenetic mechanism; conversely, inclusion of subjects with 2 -h blood glucose over $8.5 \mathrm{mmol} \cdot 1^{-1}$ will bias the interpretation towards a defect in insulin secretion.

In conclusion, a number of factors may be responsible for the discrepant results obtained in studies attempting to identify inborn errors of metabolism in the pathogenesis of Type 2 diabetes. We submit that inborn errors of current techniques, insufficient power of available methodo$\operatorname{logy}$ (in the case of beta-cell function), and confounders in the phenotyping of study subjects explain much of the existing divergences.

From the evidence reviewed here, we suggest that a reliable estimate of insulin sensitivity can be obtained from a euglycaemic insulin clamp in its 'minimal' form (7 pmol . $\min ^{-1} \cdot \mathrm{kg}^{-1}$ for $2 \mathrm{~h}$, with reduced blood sampling). Infusion of tritiated glucose may not be necessary at this insulin concentration, and fewer insulin determinations are required than with the FSIGT. Simple estimates of insulin secretion can be obtained from the early insulin response to intravenous (over the first $10 \mathrm{~min}$ ) or oral (at 30 or $40 \mathrm{~min}$ post-glucose) glucose, as these measurements have been shown to predict progression to overt diabetes $[10,47]$.

Acknowledgements. The experimental results used for this discussion are from studies supported by grants from the Sigrid Juselius Foundation, the Perklén Foundation and Finska Lakaresallskapet.

\section{References}

1. Barnett A, Eff C, Leslie D, Pyke D (1981) Diabetes in identical twins - a study of 200 pairs. Diabetologia 20: 87-93

2. Köbberling J, Tillil H (1982) Empirical risk figures for first degree relatives of non-insulin dependent diabetics. In: Köbberling J, Tattersall R (eds) The genetics of diabetes mellitus. Academic Press, London, pp 201-209

3. Yki-Järvinen H (1990) Acute and chronic effects of hyperglycaemia on glucose metabolism. Diabetologia 33: 579-585

4. Cerasi E, Luft R (1967) The plasma insulin response to glucose infusion in healthy subjects and in diabetes mellitus. Acta Endocrinol 55: 278-304

5. Cerasi E, Luft R (1967) Further studies on healthy subjects with low and high insulin response to glucose infusion. Acta Endocrinol 55:305-329

6. O'Rahilly SP, Nugent Z, Rudenski AS et al. (1986) Beta-cell dysfunction, rather than insulin-insensitivity, is the primary defect in familial type 2 diabetes. Lancet 2: 360-364

7. Lillioja S, Mott DM, Howard BV et al. (1988) Impaired glucose tolerance as a disorder of insulin action. Longitudinal and crosssectional studies in Pima Indians. NEngl J Med 318: 1217-1225

8. Leslie RDG, Ganash A, Volkmann HP, Hanning L, Alberti KGMM (1988) Insensitivity to insulin in offspring of non-insulin dependent diabetic patients. Diab Nutr Metab 3: 235-237

9. Eriksson J, Franssila-Kallunki A, Ekstrand A et al. (1989) Early metabolic defects in persons at increased risk for non-insulin dependent diabetes mellitus. NEngl J Med 321:337-343

10. Warram JH, Martic BC, Krolewski AS, Soeldner JS, Kahn CR (1990) Slow glucose removal rate and hyperinsulinemia precede the development of type II diabetes in the offspring of diabetic patients. Ann Intern Med 113: 909-915

11. Johnston C, Ward WK, Beard JC, McKnight B, Porte Jr D (1990) Islet function and insulin sensitivity in non-diabetic offspring of conjugal type 2 diabetic patients. Diabetic Med 7: 110-125

12. Ho LT, Chang ZY, Wang JT, Liu YF, Chen Y-DI, Reaven GM (1990) Insulin insensitivity in offspring of parents with type 2 diabetes mellitus. Diabetic Med 7: 31-34

13. Osei K, Cottrell DA, Orabella MM(1991) Insulin sensitivity, glucose effectiveness, and body fat distribution pattern in nondiabetic offspring of patients with NIDDM. Diabetes Care 14: $890-896$

14. Skarfors ET, Selinus KI, Lithell AH (1991) Risk factors for developing non-insulin dependent diabetes: a 10 year follow-up of men in Uppsala. BMJ 303: 755-760

15. Mitrakou A, Kelley D, Mokan M et al. (1992) Role of reduced suppression of glucose production and early insulin release in impaired glucose tolerance. N Engl J Med 326: 22-29

16. Vaag AA, Henriksen JE, Beck-Nielsen H (1992) Decreased insulin activation of glycogen synthase in skeletal muscles in young nonobese Caucasian first-degree relatives of patients with non-insulin dependent diabetes mellitus. J Clin Invest 89: 782-788

17. Martin BC, Warram JH, Krolewski AS, Bergman RN, Soeldner JS, Kahn CR (1992) Role of glucose and insulin resistance in the development of type 2 diabetes mellitus: results of a 25 -year follow-up study. Lancet 340: 925-929

18. Pimenta W, Mitrakou A, Capani F, Yki-Järvinen H, Gerich J (1992) $\beta$-cell dysfunction with normal insulin sensitivity in glucose tolerant first-degree relatives of Caucasian NIDDM patients. Diabetes 41 (Suppl 1): 143A (Abstract)

19. Groop L (1982) Heterogeneity of type I diabetes. A study of clinical, genetic, immunological and metabolic aspects. Thesis, University of Helsinki

20. Hosker JP, Matthews DR, Rudenski AS et al. (1985) Continuous infusion of glucose with model assessment: measurement of insulin resistance and B-cell function in man. Diabetologia 28: 401411

21. Galvin P, Ward G, Walters J et al. (1992) A simple method for quantitation of insulin sensitivity and insulin release from an intravenous glucose tolerance test. Diabetic Med 9: 921-928 
22. Bergman RN, Ider YZ, Bowden CR, Cobelli C (1979) Quantitative estimation of insulin sensitivity. Am J Physiol 236: E667E677

23. DeFronzo RA, Tobin JD, Andres R (1979) Glucose clamp technique: a method for quantifying insulin secretion and resistance. Am J Physiol 237: E214-E223

24. Groop LC, Bonadonna RC, Del Prato S et al. (1989) Glucose and free fatty acid metabolism in non-insulin dependent diabetes mellitus. Evidence for multiple sites of insulin resistance. J Clin Invest 84: 205-213

25. Cobelli C, Mari A, Ferrannini E (1987) The non-steady state problem: error analysis of Steele's model and developments for glucose kinetics. Am J Physiol 252: E679-E687

26. DeFronzo RA, Ferrannini E (1982) Influence of plasma glucose and insulin concentration on plasma glucose clearance in man. Diabetes 31:683-688

27. Schalin-Jäntti C, Härkönen M, Groop LC (1992) Impaired activation of glycogen synthase in people at increased risk for developing NIDDM. Diabetes 41: 598-604

28. Mandarino LJ, Consoli A, Kelley DE, Reilly JJ, Nurjhan N (1990) Fasting hyperglycaemia normalizes oxidative and nonoxidative pathways of insulin-stimulated glucose metabolism in non-insulin-dependent diabetes mellitus. J Clin Endocrinol Metab 71: 1544-1551

29. Eriksson J, Ekstrand A, Franssila-Kallunki A et al. (1989) Hyperglycaemia compensates for impaired glucose disposal in first-degree relatives of NIDDM patients with normal glucose tolerance. Acta Endocrinol 120: 11 (Abstract)

30. Mitrakou A, Vuorinen-Markkola H, Raptis G et al. (1992) Simultaneous assessment of insulin secretion and insulin sensitivity using a hyperglycaemic clamp. J Clin Endocrinol Metab 75:379382

31. Shulman GI, Rothman DL, Jue T, Stei P, DeFronzo RA, Shulman GI (1990) Quantitation of muscle glycogen synthesis in normal subjects with non-insulin dependent diabetes by ${ }^{13} \mathrm{C}$ nuclear magnetic resonance spectroscopy. N Engl J Med 322: 223-228

32. Mitrakou A, Kelley D, Veneman T et al. (1990) Contribution of abnormal muscle and liver glucose metabolism to postprandial hyperglycaemia in NIDDM. Diabetes 39: 1381-1390

33. Ferrannini E, Björkman O, Reichard GA et al. (1985) The disposal of an oral glucose load in healthy subjects. A quantitative study. Diabetes 34: $580-588$

34. Ferrannini E, Cobelli C (1987) The kinetics of insulin in man. Diab Metab Rev 3:335-363
35. Ferrannini F, Pilo A (1979) Pattern of insulin delivery after intravenous glucose injection in man and its relation to plasma glucose disappearance. J Clin Invest 64: 243-254

36. Ward WK, Bogliano DC, McKnight B, Halter J, Porte Jr D (1984) Diminished B cell secretory capacity in patients with noninsulin-dependent diabetes mellitus. J Clin Invest 74: 1318-1328

37. Mikines KJ, Farrell PA, Sonne B, Tronier B, Galbo H (1988) Postexercise dose-response relationship between the plasma glucose and insulin secretion. J Appl Physiol 64(3): 988--999

38. Polonsky KS, Given BD, Van Cauter E (1988) Twenty-four-hour profiles and pulsatile patterns of insulin secretion in normal and obese subjects. J Clin Invest $81: 442-448$

39. Polonsky KS, Given BD, Hirsch LJ et al. (1988) Abnormal patterns of insulin secretion in non-insulin-dependent diabetes mellitus. N Engl J Med 318: 1231-1239

40. Temple R, Clark PMS, Hales CN (1992) Measurement of insulin secretion in type 2 diabetes: problems and pitfalls. Diabetic Med 9: 503-512

41. Roeder M, Eriksson J, Hartling S, Groop L, Binder C (1990) Proinsulin response to hyperglycaemic clamp in type 2 diabetic patients and in their relatives. Diabetologia 33 (Suppl 1): A86 (Abstract)

42. Osei K, Cottrell DA, Bossetti BA (1992) Black-white differences in insulin sensitivity and glucose effectiveness. Diabetes 41 (Suppl 1): 63A (Abstract)

43. McKeigue PM, Pierpoint T, Ferrie JE, Marmot MG (1992) Relationship of glucose intolerance and hyperinsulinaemia to body fat pattern in South Asians and Europeans. Diabetologia 35: 785-791

44. Ferrannini E, Buzzigoli G, Bonadonna R et al. (1987) Insulin resistance in essential hypertension. N Engl J Med 317:350-357

45. Arner P, Pollare T, Lithell H (1991) Different aetiologies of type 2 (non-insulin-dependent) diabetes mellitus in obese and non-obese subjects. Diabetologia 34: 483-487

46. Banerji MA, Lebovitz HE (1992) Insulin action in black Americans with NIDDM. Diabetes Care 15: 1295-1302

47. Eriksson K-F (1992) Prevention of non-insulin dependent diabetes mellitus. Thesis, University of Lund, Malmö

Dr. L.C.Groop

Department of Endocrinology

University of Lund

Malmö General Hospital

S-21401 Malmö

Sweden 